\title{
Magnetic Property Study of Nickel Cerium Doped Zinc Ferrite Nano Particles
}

\author{
S.K.A. Ahamed \\ Kandu Sahib \\ Asso.Prof./ECE \\ Sethu Inst. of Tech., \\ Pulloor - 626115, \\ Tamilnadu, India
}

\author{
Vasant Naidu \\ Professor/ECE \\ Sethu Inst. of Tech., \\ Pulloor - 626115, \\ Tamilnadu, India
}

\author{
S. Amalorpava Mary \\ Rajee \\ Asst.Prof/ECE \\ Sethu Inst. of Tech., \\ Pulloor - 626115, \\ Tamilnadu, India
}

\author{
S. Vijay Anand \\ Asst.Prof./ECE \\ Sethu Inst. of Tech., \\ Pulloor - 626115, \\ Tamilnadu, India
}

\begin{abstract}
Nano-particles of polycrystalline $\mathrm{Zn} \mathrm{Fe}_{2} \mathrm{O}_{4}$ doped with, Ni and $\mathrm{Ce}\left(\mathrm{Zn} \mathrm{Ni}_{\mathrm{y}} \mathrm{Ce}_{\mathrm{x}} \mathrm{Fe}_{2-\mathrm{x}-\mathrm{y}} \mathrm{O}_{4}\right.$, where $\mathrm{x}=0.01,0.012,0.014$, $0.016, \mathrm{y}=0.003$ ) was prepared by sol-gel auto combustion route. The microwave sintered ferrite was characterized and the nano size was confirmed by XRD and the SEM monographs. The EDAX studies confirm the composition of $\mathrm{Ni}$, Ce doped Zn-ferrites and VSM studies show the behaviour of coercivity and Saturation magnetization. The permittivity increased with the increase in Ni-Ce doping concentration.
\end{abstract}

Key Words: Ce-Ni doped Zn ferrite; Low permittivity Nanomaterials; Sol-gel route

\section{INTRODUCTION}

Ferrites have technological importance [1], and further nano ferrites play an important role in the miniaturization of several microwave device applications[2]. Zn-Ni Ferrites are one of the most versatile magnetic materials [3-4] with high resistivity, low dielectric losses [5], mechanical hardness [6], high Curie temperature and chemical stability [7] and reasonable cost, therefore these materials are used as low or high-frequency devices. There are many literatures available explaining their strong dependence on chemical composition [8], porosity, grain size [9] etc.

since the magnetic property of $\mathrm{Zn}-\mathrm{Ni}$ ferrites depends upon the relatively higher concentration of $\mathrm{Zn} \mathrm{[10-11],} \mathrm{in}$ continuation to this, our work on $\mathrm{Zn} \mathrm{Ni}_{\mathrm{y}} \mathrm{Ce}_{\mathrm{x}} \mathrm{Fe}_{2-\mathrm{x}-\mathrm{y}} \mathrm{O}_{4}$ has been carried out, by keeping $\mathrm{x}$ as $0.01,0.012,0.014,0.016$ and $\mathrm{y}$ as 0.003 . Consequently the difference in nature of cation and its distribution in spinel as well as ionic states [1213] of the metal ions has been studied and their presence in Aand B-sites was analysed by using X-ray diffraction (XRD), and Infrared spectra (FTIR) to provide a meaningful correlation in terms of their structure and effective changes in the environs of ions [14].

\section{EXPERIMENTAL PROCEDURE}

2.1 Synthesis Technique A set of Zinc Nickel Cerium ferrites $\left(\mathrm{Zn} \mathrm{Ni}_{\mathrm{y}} \mathrm{Ce}_{\mathrm{x}} \mathrm{Fe}_{2-\mathrm{x}-\mathrm{y}} \mathrm{O}_{4}\right)$ was synthesized by solgel auto-combustion method [4]. The required amount of metal nitrates and citric acid are taken so as to have a molar ratio of $1: 1$ and dissolved in $100 \mathrm{ml}$ of deionized water. A required amount of ammonia is added into the solution in order to adjust the $\mathrm{pH}$ value to about 7 since base catalysts are employed in order to speed up the reaction. Sol so formed is poured in a silica crucible and heated at $135^{\circ} \mathrm{C}$ under constant stirring to condensate into a xerogel. Dried gel is formed. Finally in dehydration process the xero gel (dried gel) is obtained by heating the product to $100^{\circ} \mathrm{C}$ temperature. Citric acid helps the homogenous distribution of the metal ions to get segregated from the solutions. The dried gel is crushed and pellatised and later subjected to microwave sintering [15]. The grain size of the nanoferrite is determined using Scherrer's equation. Using the knowledge of site preference of the ions and the ionic size data of the respective ions, the cation distribution has been estimated theoretically using the following formula proposed $[9,13]$. Where $r_{a}$ and $r_{b}$ are the radii of the ions present in $\mathrm{A}$-and $\mathrm{B}$-site, respectively, whereas $r_{o}$ is the ionic radius of oxygen. The experimental magnetic moment is calculated from the following formula [14].

$$
\eta=\frac{\left[M_{W} * M_{S}\right]}{5585}
$$

Where MW is the molecular weight of the sample and Ms is the saturation magnetization in emu/g.

\subsection{XRD and EDAX Studies}

The phase composition of fine ferrite powder was carried out using PAN analytical X'pert PRO diffraction meter with $\mathrm{Cu}$ $\mathrm{K}_{\alpha}$ radiation $\left(\lambda=1.54^{\circ} \mathrm{A}\right)$ at $40 \mathrm{KV}$ and $30 \mathrm{~mA}$ with a scanning rate of $0.01 \%$ and scan speed of $1 \%$ min in a $2 \theta$ range of 10 $80^{\circ} \mathrm{A}$. The crystallite size was calculated by the Scherrer formula. The energy dispersive studies (EDAX) were done on Genesis EDAX to confirm the presence of chemical composition of the powder.

\subsection{FTIR Analysis}

Infrared absorption spectra in the range of $364-541 \mathrm{~cm}-1$ were recorded at room temperature by using SHIMADZU FTIR spectrum one spectrometer using $\mathrm{KBr}$ pellet method. The spectrum transmittance $(\%)$ against wave number $(\mathrm{m}-1)$ is used for interpretation of the results.

\subsection{SEM Studies}

The micro structure and the morphological studies of the nano ferrite powder were carried out using a scanning electron microscope (HITACHI model S-3000H). The grain size was determined from the SEM microphotographs.

\subsection{Magnetic Measurements}

Commercial vibrating sample magnetometer (VSM) Lakeshore (Model 73009) was used for analyzing the Magnetic measurements of the samples. With the maximal applied magnetic fields up to $0.95 \mathrm{~T}$ magnetic hysteresis loops were measured at room temperature. The Magnetic field sweep rate was kept at $5 \mathrm{Oe} / \mathrm{s}$ for all measurements, so that the measurement of hysteresis loops with maximum field of $0.989 \mathrm{~T}$ was taken at an interval of $3 \mathrm{hrs}$. The saturation magnetization $\left(\mathrm{M}_{\mathrm{S}}\right)$, coercive force $\left(\mathrm{H}_{\mathrm{C}}\right)$ and remanent 
Table 1 XRD cation distribution of $\mathrm{Zn} \mathrm{Ni}_{\mathrm{y}} \mathrm{Ce}_{\mathrm{x}} \mathrm{Fe}_{2-\mathrm{x}-\mathrm{y}} \mathrm{O}_{4}$

\begin{tabular}{|c|c|c|c|c|}
\hline $\begin{array}{c}\mathrm{Zn} \mathrm{Ni}_{\mathrm{y}} \mathrm{Ce}_{\mathrm{x}} \\
\mathrm{Fe}_{2-\mathrm{x}-\mathrm{y}} \mathrm{O}_{4}\end{array}$ & $\begin{array}{l}x=0.01 \\
y=0.003\end{array}$ & $\begin{array}{l}x=0.012 \\
y=0.003\end{array}$ & $\begin{array}{l}x=0.014 \\
y=0.003\end{array}$ & $\begin{array}{l}x=0.016 \\
y=0.003\end{array}$ \\
\hline $\mathbf{a}\left(\mathbf{A}^{\mathbf{0}}\right)$ & 8.46 & 8.49 & 8.46 & 8.46 \\
\hline $\mathbf{D}(\mathbf{n m})$ & 58.95 & 65.15 & 62.48 & 68.75 \\
\hline $\mathrm{d}_{\mathrm{x}} \times 10^{3} \mathrm{gcm}-3$ & 3.864 & 3.687 & 3.746 & 3.649 \\
\hline Porosity & 0.315 & 0.346 & 0.282 & 0.231 \\
\hline $\begin{array}{c}\text { Observed } \\
\text { contents (Ni) }\end{array}$ & 0.003 & 0.003 & 0.003 & 0.003 \\
\hline $\begin{array}{l}\text { Observed } \\
\text { Contents (Ce) }\end{array}$ & 0.01 & 0.012 & 0.014 & 0.016 \\
\hline$( \pm 0.01 \mathrm{~mol}) \mathrm{Fe}$ & 1.987 & 1.985 & 1.983 & 1.981 \\
\hline
\end{tabular}

magnetization $\left(\mathrm{M}_{\mathrm{R}}\right)$ and magnetic moment $(\eta)$ has been determined from magnetization study.[9].

\subsection{Electrical Measurements}

N4L LCR meter was used for the Electrical measurements such as capacitance and permittivity. The experimental set up for measuring the dielectric properties in the microwave region consisted of a pallet holder connected to the N4L LCR meter interfacing the computer [11]. The microwave properties of the four samples $\mathrm{Ce}(\mathrm{x})$ - $\mathrm{Ni}$ (y) doped magnesium ferrite $x=0.01,0.012,0.014,0.016$ and $y=0.003$, were investigated at the frequency range from $10 \mathrm{MHz}$ to 20 $\mathrm{GHz}$

\section{RESULTS AND DISCUSSION \\ 3.1 X-ray Diffraction}

The Figure. 1 shows the X-ray diffraction patterns of microwave sintered ferrite powder of different $\mathrm{Ni}-\mathrm{Ce}$ doping concentration. The observed peaks of the diffraction patterns were indexed and corresponding " $\mathrm{d}$ " were calculated and compared with the JCPDS card number 08-0234. The Ni-Ce doped Zinc ferrite was found to exhibit the single- phase cubic spinel structure.

Similar diffraction pattern was observed for Ce ferrite by E.Ateia [16] and for Zinc Nickel ferrite by Chandra Prakash [17] et.al and Vasant Naidu et.al [18] and reported the existence of single phase cubic spinal structure.

From the broad peak $3,1,1$ of the XRD patterns, the Lattice constant [19] and particle size of the ferrites were calculated as mentioned in the Table 1 using the Bragg's equation(equation 2) [14].

$$
\mathrm{a}=\mathrm{d}_{\mathrm{hkl}} \sqrt{\mathrm{h}^{2}+\mathrm{k}^{2}+\mathrm{l}^{2}}
$$

Where hkl are the indices of mentioned planes. It was seen that the particle size ranged between $58.95 \mathrm{~nm}$ and $68.75 \mathrm{~nm}$.. The values of lattice constant were determined by a careful selection of cations in the octahedral and tetrahedral sites of ferrites. As it is well known that the degree of the replacement of the cations by the other ions the host lattice depends on the cations radius of the substituent [20]. The particle size was calculated from the full width at half maximum (FWHM) values of 3,1,1 plane of the X-ray diffraction using Scherrer's Formula(equation 3).

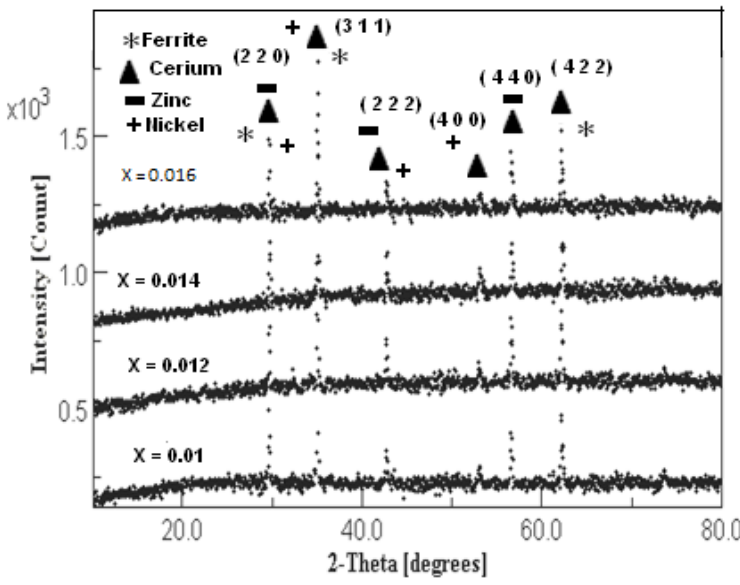

Fig 1 XRD patterns of nano-particles of $\mathrm{Zn} \mathrm{Ni}_{\mathrm{y}} \mathrm{Ce}_{\mathrm{x}} \mathrm{Fe}_{2}$ $x-y=0,0.0 .01,0.012,0.014,0.016, y=0.003$

This difference suggests that a diffusion inhibition was induced by the inclusion of rare-earth ions during the formation of the mixed metal oxide.

\subsection{EDAX}

The EDAX spectra ( Figure 2 and 3) obtained from the center of $\mathrm{Zn}$ substituted $\mathrm{Ni} \mathrm{Ce}$ ferrite grains indicated the presence of large concentration of $\mathrm{Zn}$ with in the energy range of $9 \mathrm{eV}$ and $10 \mathrm{eV}, \mathrm{Ni}$ in between $7.5 \mathrm{eV}$ and $8.8 \mathrm{eV}$ and $\mathrm{Ce}$ was seen between $4.25 \mathrm{eV}$ and $6.25 \mathrm{eV}$ where as iron was seen between the energy range of $6.25 \mathrm{eV}$ and $7 \mathrm{eV}$.

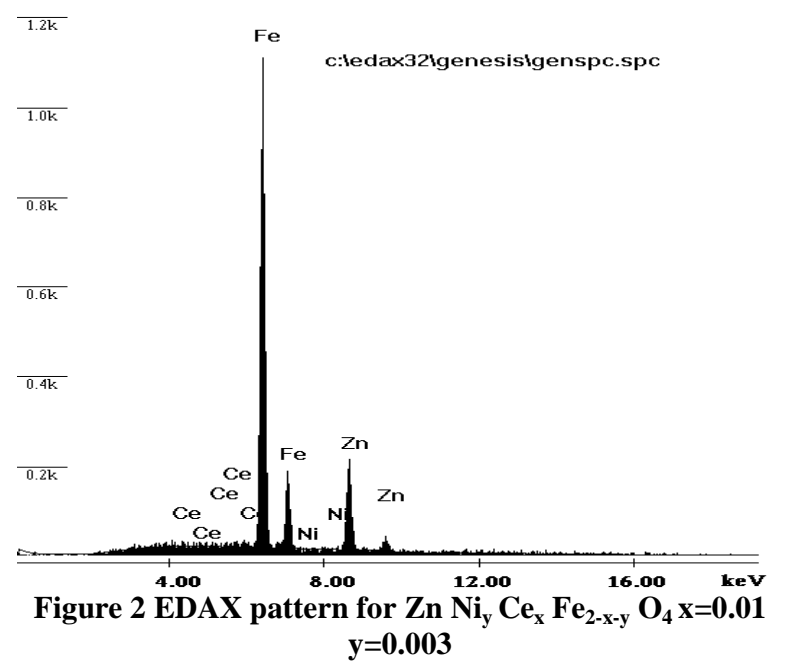

$\mathrm{D}=\frac{0.94 \lambda}{\beta \cos \theta}$ 


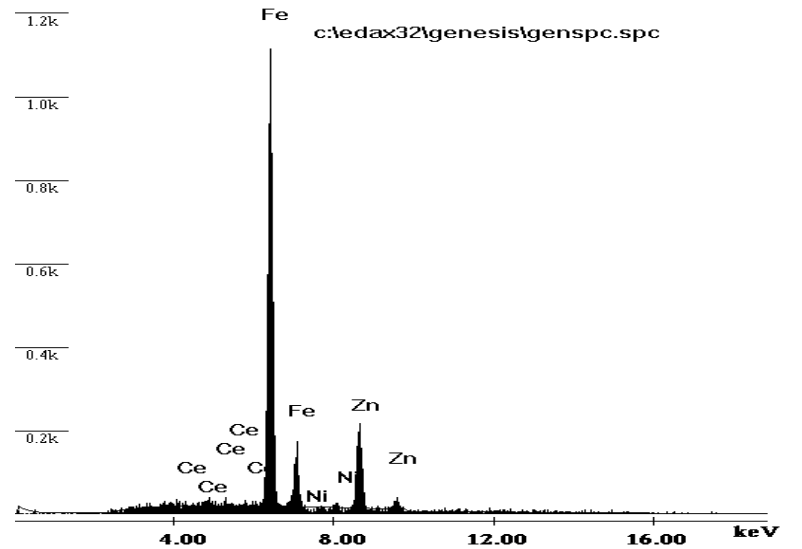

Figure 3 EDAX pattern for $\mathrm{Zn} \mathrm{Ni}_{\mathrm{y}} \mathrm{Ce}_{\mathrm{x}} \mathrm{Fe}_{2-\mathrm{x}-\mathrm{y}} \mathrm{O}_{4} \mathrm{x}=0.012$ $\mathbf{y}=\mathbf{0 . 0 0 3}$.

\subsection{SEM Analysis}

From the scanning electron microscope (SEM) scan patterns of the unsubstituted specimen (Figure 4) shows the presence of a monophasic homogeneous micro-structure with an average grain size $0.42 \mathrm{~nm}$. Whereas, the $\mathrm{Ni}-\mathrm{Ce}$ doped specimens show a bi-phasic microstructure. It constituted of dark ferrite matrix grains and small whitish grain at the grain junction/boundary. As reported by Sattar et, al [21] the rare earth ions occupy either the iron positions or go to the grain boundaries. However we have to exclude the probability that the rare earth ions occupy the $\mathrm{A}$ - site of $\mathrm{Fe}^{3+}$ ions. This is due to the fact that the tetrahedral sites are small to be occupied by the large rare earth ions which have large ionic radius. Of course the probability of occupancy of the octahedral (B-site) by the rare earth ions will increase with decrease in the $\mathrm{R}$ ionic radius. This indicated whitish grains were of $\mathrm{CeFeO}_{3}$ The amount of $\mathrm{CeFeO}_{3}$ was maximum in $\mathrm{x}^{1 / 4} \quad 0.014$ composition. The grain size of matrix phase was maximum in $\mathrm{x}^{1 / 4} 0.01$ composition. Relatively lower grain size of ferrite matrix in $x^{1 / 4} 0.01$ compositions may be due to the grain growth inhibition caused by $\mathrm{CeFeO}_{3}$.

The scanning electron (SEM) micrograph of the unsubstituted zinc ferrite specimen (Figure 4), show the presence of a monophasic homogeneous microstructure with an average grain size $0.42 \mathrm{~nm}$. Whereas, Ni-Ce doped specimens (Figure $5,6,7)$ show the bi-phasic microstructure, which constitutes of dark ferrite matrix grains and small whitish grain at the grain junction/boundary. As proposed by Sattar et,al [21] the rare earth ions occupy either the iron positions or go to the grain boundaries. However we will exclude the probability of the rare earth ions occupying the $\mathrm{A}$ - site of $\mathrm{Fe}^{3+}$ ions, this is due to the fact that the tetrahedral sites are small and cannot be occupied by the large rare earth ions due to their large ionic radius. The probability of occupancy in the octahedral (B-site) site will decrease with increase in the rare earth ions ionic radius $\mathrm{R}$. These whitish grains of $\mathrm{CeFeO}_{3}$ are in-circled in Figure 4,5,6,7. It is seen that the grain size of matrix phase was maximum for $\left(\mathrm{x}^{1 / 4}\right) 0.014$ composition of $\mathrm{CeFeO}_{3}$ doping. Here the Relatively lower grain size of ferrite matrix in for 0.01 compositions may be due to the grain growth inhibition caused by the doping of $\mathrm{CeFeO}_{3}$.

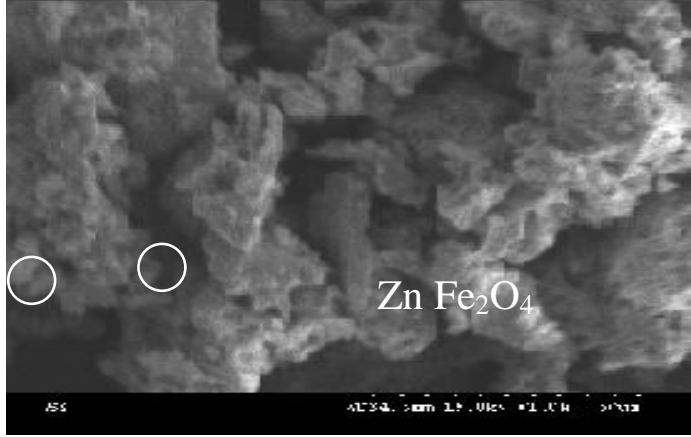

Figure $4 \mathrm{Zn} \mathrm{Ni}_{\mathrm{y}} \mathrm{Ce}_{\mathrm{x}} \mathrm{Fe}_{2-\mathrm{x}-\mathrm{y}} \mathrm{O}_{4} \mathrm{x}=0.001, \mathrm{y}=0.003$

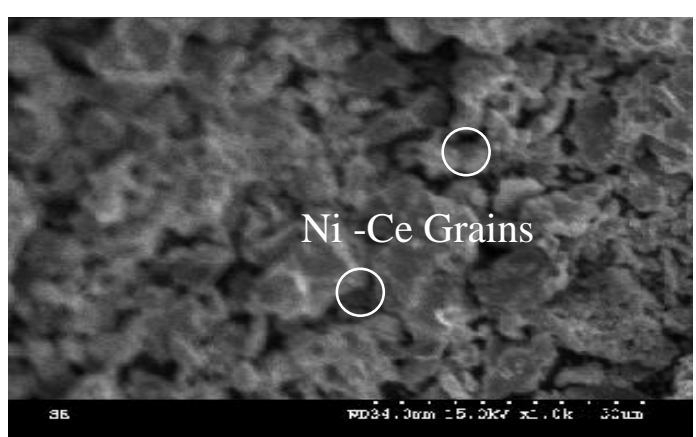

Figure $5 \mathrm{Zn} \mathrm{Ni}_{\mathrm{y}} \mathrm{Ce}_{\mathrm{x}} \mathrm{Fe}_{2-\mathrm{x}-\mathrm{y}} \mathrm{O}_{4} \mathrm{x}=0.012, \mathrm{y}=0.003$

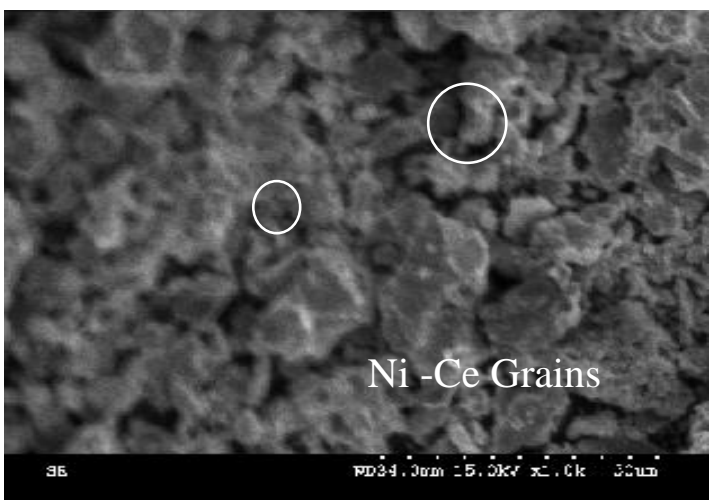

Figure $6 \mathrm{Zn} \mathrm{Ni}_{\mathrm{v}} \mathrm{Ce}_{\mathrm{x}} \mathrm{Fe}_{2-\mathrm{x}-\mathrm{v}} \mathrm{O}_{4} \mathrm{x}=0.014, \mathrm{y}=0.003$

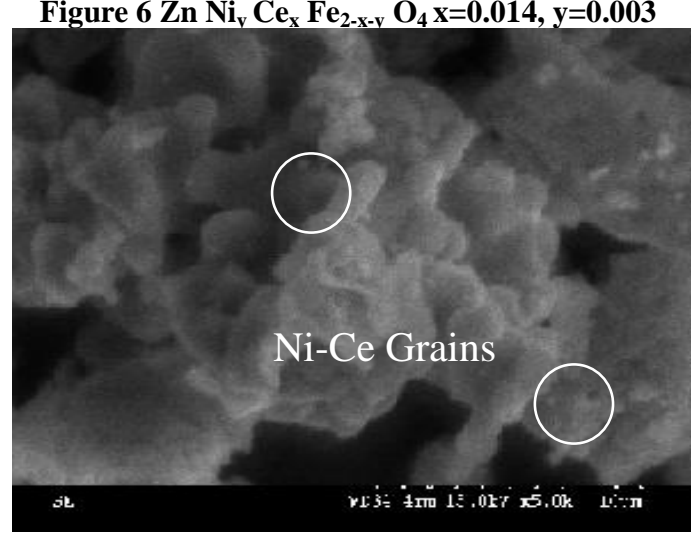

Figure $7 \mathrm{Zn} \mathrm{Ni}_{y} \mathrm{Ce}_{x} \mathrm{Fe}_{2-x-y} \mathrm{O}_{4} \mathrm{x}=0.016, \quad y=0.003$

\subsection{Hysteresis Studies}

Figure 8 shows the magnetic loop of different $\mathrm{Zn} \mathrm{Ni} \mathrm{Ne}_{\mathrm{x}} \mathrm{Fe}_{2}$ $x-y$ $\mathrm{O}_{4}$ ferrites. Saturation magnetization $\left(\mathrm{M}_{\mathrm{s}}\right)$ values of different compositions are given in Figure.8. It was seen that the $\mathrm{M}_{\mathrm{s}}$ of strongly doped(x=0.016) ferrites was higher than weakly doped $(x=0.01)$ ferrite. The permeability of the 
strongly doped ferrites was increasing with respect to the weakly doped ferrite Table 2 .

The values of magnetic parameters such as $\mathrm{M}_{\mathrm{S}}, \mathrm{H}_{\mathrm{C}}$, $\mathrm{M}_{\mathrm{R}}$ of nano particles of $\mathrm{Zn} \mathrm{Ni}_{\mathrm{y}} \mathrm{Ce}_{\mathrm{x}} \mathrm{Fe}_{2-\mathrm{x}-\mathrm{y}} \mathrm{O}_{4}$ obtained from the VSM data are shown in Table 2. It is seen that there is a linear decrease in Coercivity, whereas a linear increase in Magnetic saturation is seen with the increased doping concentration. The doping of Cerium content induces a polarto-non polar phase transition within the polar region in $\mathrm{Zn} \mathrm{Ni}_{\mathrm{y}}$ $\mathrm{Ce}_{\mathrm{x}} \mathrm{Fe}_{2-\mathrm{x} \text {-y }} \mathrm{O}_{4}$. This is due to the Cerium substitution causing the spontaneous magnetization, which in turn significantly enhances the composition-driven transition of in $\mathrm{Zn} \mathrm{Ni}_{\mathrm{y}} \mathrm{Ce}_{\mathrm{x}}$ $\mathrm{Fe}_{2-x-y} \mathrm{O}_{4}$ from a rhombohedral to an orthorhombic phase.

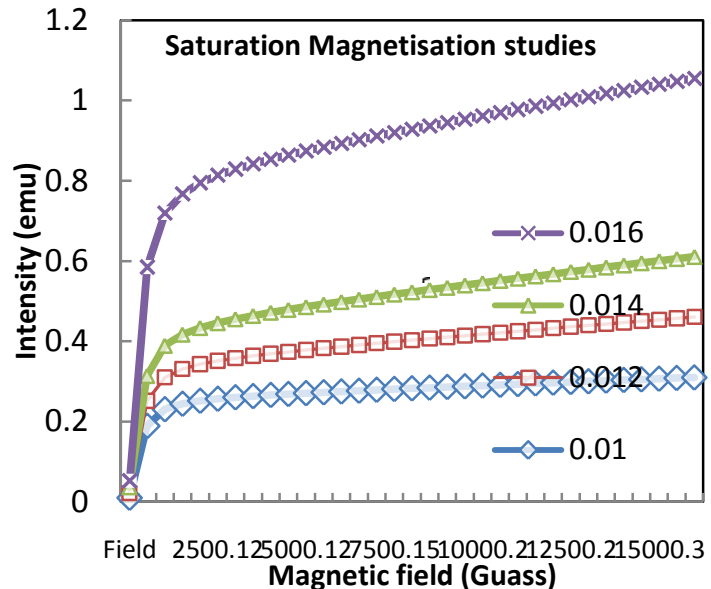

Figure 8 Saturation magnetization(Ms) of $\mathrm{Zn} \mathrm{Ni}_{\mathrm{y}} \mathrm{Ce}_{\mathrm{x}} \mathrm{Fe}_{2}$ $x-y=O_{4}$ Ferrite, $x=0.01,0.012,0.014,0.016$, and $y=0.003$

Table 2 Magnetic saturation,Coercivity, Retentivity for $\mathrm{Zn} \mathrm{Ni} \mathrm{Ce}_{\mathrm{x}} \mathrm{Fe}_{2-\mathrm{x}-\mathrm{y}} \mathrm{O}_{4}$

\begin{tabular}{|c|c|c|c|c|c|c|c|}
\hline \multicolumn{2}{|c|}{$\mathbf{Z n ~ N i}_{\mathbf{y}} \mathbf{C e}_{\mathbf{x}} \mathbf{F e}_{2-\mathrm{x}-\mathbf{y}} \mathbf{O}_{\mathbf{4}}$} & $\begin{array}{c}\text { Magnetic } \\
\text { Saturation } \\
\mathbf{M}_{\mathbf{S}}(\mathbf{e m u})\end{array}$ & $\begin{array}{c}\text { Magnetic } \\
\text { moment } \\
(\eta)\end{array}$ & $\begin{array}{c}\text { Coerci- } \\
\text { vity } \\
\mathbf{H}_{\mathbf{C}}(\mathbf{G})\end{array}$ & $\begin{array}{c}\text { Retenti- } \\
\mathbf{v i t y} \mathbf{M}_{\mathbf{R}} \\
(\mathbf{e m u})\end{array}$ & $\boldsymbol{\varepsilon}_{\mathbf{r}}$ & $\boldsymbol{\varepsilon}_{\mathbf{r}}{ }^{\prime}$ \\
\hline $\mathrm{X}=0.01$ & $\mathrm{y}=0.003$ & 0.063 & 0.0051 & 160.34 & 0.0148 & 0.5 & 0.8 \\
$\mathrm{x}=0.012$ & $\mathrm{y}=0.003$ & 0.168 & 0.0139 & 158.53 & 0.2954 & 2.45 & 2.5 \\
$\mathrm{x}=0.014$ & $\mathrm{y}=0.003$ & 0.325 & 0.0272 & 146.41 & 0.7799 & 2.7 & 3.1 \\
$\mathrm{x}=0.016$ & $\mathrm{y}=0.003$ & 0.463 & 0.0397 & 140.11 & 0.1828 & 3.8 & 4.4 \\
\hline
\end{tabular}

\subsection{FTIR Study}

The study of far-infrared spectra is an important tool to get the information about the position of ions in the crystal. The spectra show two major absorption bands in the given frequency range. The high and low frequency absorption bands $\left(v_{1}, v_{2}\right)$ are observed in a frequency range of $3.64 \times 10^{4}$ $\mathrm{m}^{-1}$ to $3.89 \times 10^{4} \mathrm{~m}^{-1}$ and $3.51 \times 10^{4} \mathrm{~m}^{-1}$ to $5.41 \times 10^{4} \mathrm{~m}^{-1}$, which is attributed to tetrahedral and octahedral complexes of $\mathrm{Fe}^{3+} \mathrm{O}^{2-}$.

These two bands have been reported by Waldron [22] in spinel structure of ferrite. No shift of absorption band $v_{1}$ is observed. The absorption band $v_{2}$ is slightly shifted to a higher frequency side with addition of $\mathrm{R}$ ions and is attributed to increase in bond length on the B-site [23-24]. This suggests that the rare-earth ions occupy the B-site. The difference in frequencies between $v_{1}$ and $v_{2}$ is due to changes in bond length $\left(\mathrm{Fe}^{3+}-\mathrm{O}^{2-}\right)$ at tetrahedral and octahedral sites [25]. The broadening of the $v_{2}$ band is observed in rare-earth added $\mathrm{ZnFe}_{2} \mathrm{O}_{4}$, which suggests the occupancy of rare-earth ions on the B-sites [26].

The IR band width depends on the cation distribution of the material. The Shift occur in the frequency band $v_{1}, v_{2}$ for each octahedral and tetrahedral sites are due to perturbation occurring in the $\mathrm{Fe}^{3+}-\mathrm{O}^{2-}$ band by introducing $\mathrm{Ce}$ content. The potential energy constant and magnetic moment data should provide information about the change of environs and energy conditions when $\mathrm{Ni}$ and $\mathrm{Ce}$ are substituted in $\mathrm{Zn}$ ferrite. Although the order of increase of ionic size is like $\mathrm{Ni}$, $\mathrm{Ce}$ and $\mathrm{Zn}$ the values of magnetic moment Table 2 and force constant show a deviation for $\mathrm{Ni}$ substituted $\mathrm{Zn}$ ferrite. The deviations of ionic moment verses magnetic moment and bond length versus force constant of these ferrites are accounted for by a substantial role of crystal field effect [26] initiated by $\mathrm{Zn}$ ions.

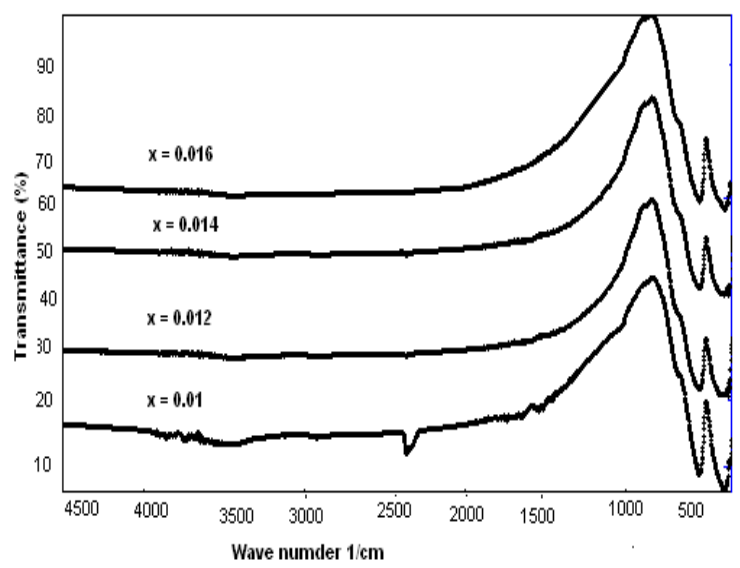

Figure 9 FTIR spectra of nano-particles of $\mathrm{Zn} \mathrm{Ni}_{\mathrm{y}} \mathrm{Ce}_{\mathrm{x}}$ $\mathrm{Fe}_{2-\mathrm{x}-\mathrm{y}} \mathrm{O}_{4}$ Ferrite, $\mathrm{x}=0.01,0.012,0.014,0.016$, and $y=0.003$ 
Table 3 FTIR to show the rare-earth ions occupation in the B-site

\begin{tabular}{|c|c|c|c|}
\hline \multirow{2}{*}{$\mathbf{Z n ~ N i}_{\mathbf{y}} \mathbf{C e}_{\mathbf{x}} \mathbf{F e}_{2-x-y} \mathbf{O}_{\mathbf{4}}$} & \multicolumn{2}{|c|}{ Absorption/cm } \\
\hline $\mathbf{X}$ & $\mathbf{y}$ & $\mathbf{v}_{\mathbf{1}}$ & $\mathbf{v}_{\mathbf{2}}$ \\
\hline 0.001 & 0.003 & 389.59 & 541.96 \\
\hline 0.0012 & 0.003 & 385.74 & 541.96 \\
\hline 0.0014 & 0.003 & 379.95 & 352.95 \\
\hline 0.0016 & 0.003 & 364.52 & 351.02 \\
\hline
\end{tabular}

\subsection{Electrical Properties}

The variation of dielectric constant $\varepsilon_{\mathrm{r}}$ and dielectric loss $\varepsilon_{\mathrm{r}}$ are mentioned in Table 2 of the microwave sintered $\mathrm{Zn} \mathrm{Ni}_{\mathrm{y}} \mathrm{Ce}_{\mathrm{x}}$ $\mathrm{Fe}_{2-\mathrm{x}-\mathrm{y}} \mathrm{O}_{4}$ samples, within a frequency range of $1-20 \mathrm{KHz}$ and are shown in Figure 10 and 11. These plots show that the values of $\varepsilon_{\mathrm{r}}$ and $\varepsilon_{\mathrm{r}}$, increases with the addition of Cerium and Nickel concentration and it is also seen that, the values tend to decrease exponentially with the increase in frequency. While the value of the capacitance remains fairly constant over this frequency range. This can be explained with the Koops' model [27], according to this model, the ferrite consists of two layers, the more conducting layer due to grains and the poor conducting layer due to grain boundaries. In this nano sized ferrites, the number of grain boundaries increases, which contributes towards the dielectric constant at lower frequencies while the grains have low dielectric constants and are effective at high frequencies. A lowest value of $\varepsilon_{\mathrm{r}}=0.5$ was observed for $\mathrm{x}=0.01, \mathrm{y}=0.003$ concentrations and the higher value of $\varepsilon_{\mathrm{r}}=3.8$ was observed for $\mathrm{x}=0.016, \mathrm{y}=0.003$ concentrations. The values of dielectric loss $\left(\varepsilon_{\mathrm{r}}^{\prime}\right)$ is higher at lower frequencies and lower at higher frequencies, it is also seen that at lower frequencies the resistivity is high due to the principal effect of the grain boundaries (low resistivity regions) and therefore the energy required for the electron hopping between $\mathrm{Fe}^{2+}$ and $\mathrm{Fe}^{3+}$ at the grain boundaries is higher[27].

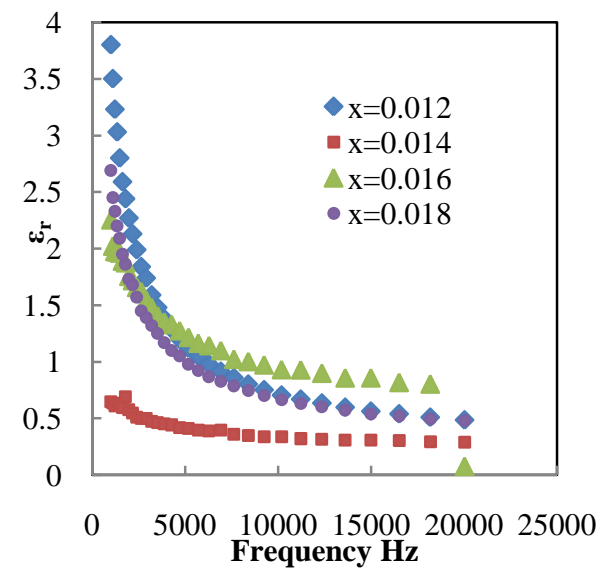

Figure10. Dielectric constant for $\mathrm{Zn} \mathrm{Ni}_{\mathrm{y}} \mathrm{Ce}_{\mathrm{x}} \mathrm{Fe}_{2-\mathrm{x}-\mathrm{y}} \mathrm{O}_{4}$

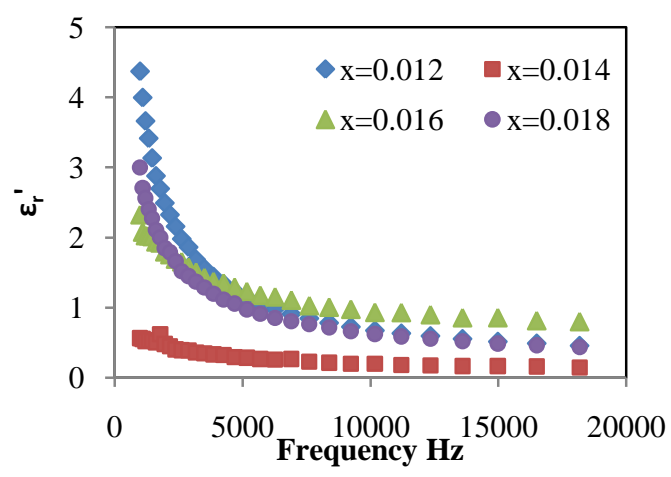

Figure 11. Dielectric loss for $\mathrm{Zn} \mathrm{Ni}_{\mathrm{y}} \mathrm{Ce}_{\mathrm{x}} \mathrm{Fe}_{2-\mathrm{x}-\mathrm{y}} \mathrm{O}_{4}$ 4. CONCLUSION

From the above experimental results, it is clearly evident that the nano size of the ferrite particles has caused increase in magnetization in Ni-Ce doped Zn Ferrite. Since Saturation magnetization and coercive force did not show a considerable rise with the increase in $\mathrm{Ni}-\mathrm{Ce}$ concentration, therefore attempt has to be made to increase the Ni-Ce concentration further. Which will be a very useful parameter to decrease in permittivity, which in turn will be useful in the construction and reducing the size of Microstrip patch antennas.

\section{ACKNOWLEDGEMENT}

Authors Dr. Vasant Naidu and S.K.A Ahamed Kandu Sahib, would like to thank Dr.V.R.K.Murthy, Professor, IIT Madras for his valuable suggestions. and also wishes to thank Dr. S. Sankaran, Director, Dr. Chandra Prakash Joint Director DRDO, New Delhi and Dr.S. Pandian, Scientist 'F' DMRL, Hyderabad for their extended support for completing this work.

\section{REFERENCES}

[1] P. I. Slick, E. P. Wohlforth, Ferrites for non microwave applications, Ferro Magnetic Materials, vol. 2, 1980, pp. $189-241$

[2] Vasant Naidu et.al Mg Sm Ferrite for Nano structured EShaped Patch Antenna studies Int. J of Computer Applications vol 30, 5, September 2011, pp 45-50.

[3] R.V Mangalaraja, Magnetic, Electrical and Dielectric behaviour of $\mathrm{Ni}_{0.8} \mathrm{Zn}_{0.2} \mathrm{Fe}_{2} \mathrm{O}_{4}$ prepared through flash combustion technique, J. Magnetism and Magnetic Material, vol 253, 1-2, 2002, pp 56-64.

[4] A.C.F.M.costa, Comparison of Nickel Zinc ferrite powder preparation by combustion reaction using different Synthesization Routes, J. Meta Stable and nano crystalline vol 20-21, 2004, pp:582-587.

[5] A.M. Abdeen, Dielectric behaviour in Ni-Zn ferrites, J. Magnetism and Magnetic Material, vol 192,1, 1999, pp 121-129.

[6] H.H.Joshi, Effect of Nickel Substitution on Structural infrared and Elastic properties of lithium ferrite, Indian J of Pure \& Applied Physics vol.45, 2007, pp596-608.

[7] C.Pramana, The temperature dependence of the Magneto Elastic Characteristics of cores for force sensors utilizing $\mathrm{Fe}_{7.0} \mathrm{Ni}_{8} \mathrm{Si}_{10} \mathrm{~B}_{12}$ amorphous alloy Indian Academy of Sciences vol.71, No.3 2008, pp. 591-597.

[8] I.Z.Rahman, T.T.Ahamed, Magnetic and Physical Characterization of nano granular $\mathrm{Ni}-\mathrm{Zn}-\mathrm{Cu}$ based ferrite 
powders, J. Meta stable and nano crystalline, vol 17, 2003 pp.9-16.

[9] J.Bera, P.K. Roy, Effect of grain size on electromagnetic properties of $\mathrm{Ni} \quad{ }_{0.7} \mathrm{Zn} \quad{ }_{0.3} \mathrm{Fe}_{2} \mathrm{O}_{4}$ ferrite with the substitution of a small fraction of lanthanum for iron, Physica B: Phys. Condens. Matter, vol 363/1-4, 2005, pp. 128-132.

[10] Y L N Murthy, I.V.Kasi Viswanath, T. Kondala Rao, Rajendra Singh., Synthesis and Characterization of Nickel Copper Ferrite, Int. J of Chem. Tech Research vol.1, No.4, 2009, pp 1308-1311.

[11] N Rezlescu, ERezlescu, C Pasnicu., and M.L Craus., Effect of the rare-earth ions on some properties of nickelzinc ferrite, J. Phys. Condens. Matter, 6, 1994, pp 5707.

[12] E.J.W. Verwey, E.L. Heilmann, Physical Properties and Cation Arrangement of Oxides with Spinel Structures I. Cation Arrangement in Spinels, J. Chem. Phys. 15, 1947, pp174.

[13] G.M Bhongale, D.K Kulkarni, V.B Sapre, Determination of cation distribution in spinels, Bull, Mater.Sci.15, 1992, pp121.

[14] Purusotham Yadoji, Microwave Sintering of Ni-Zn ferrite Comparison with conventional sintering, Mat. Sci. Eng. B98.2003, pp 269-278.

[15] A.Pradeep, P.Priyadharsini., G.Chandrasekaran, Sol-gel route of Synthesis of Nano particles of $\mathrm{MgFe}_{2} \mathrm{O}_{4}$ and XRD,FTIR and VSM study, J of Magn Mag.Mater, 320, 2008, pp 2779.

[16] E.Ateia Egypt, Effect of Gamma Irradiation on the Structural and Electrical Properties of $\mathrm{Co}_{0.5} \mathrm{Zn}_{0.5} \mathrm{Ce}_{\mathrm{y}} \mathrm{Fe}_{2-}$ y $\mathrm{O}_{4}$, J. Solids, vol.29, No.2, 2006, pp 317-328.

[17] Chandra Prakash et.al, Dielectric Properties of 0.95 $\left(\begin{array}{llllll}\mathrm{Pb}_{13 \times / 2} \mathrm{La}_{\mathrm{x}} & \mathrm{Zr}_{0.65} & \mathrm{Ti} & { }_{0.35} \mathrm{O}_{3}\end{array}\right)-0.05\left(\mathrm{Ni}_{0.8} \mathrm{Zn}_{0.2} \mathrm{Fe}_{2} \mathrm{O}_{4}\right)$ Composites Advances in Condens. Matter Phys, 2011, pp1-5.
[18] Vasant Naidu et.al, Magnetic Properties of Nano Crystalline Nickel, Samarium doped Zinc Ferrite, Int. J. Comp. App, vol 2, 2, 2011, pp18-22.

[19] P.K. Roy and J. Bera, Enhancement of the magnetic properties of $\mathrm{Ni}-\mathrm{Cu}-\mathrm{Zn}$ ferrites with the substitution of a small fraction of lanthanum for iron, Materials Research Bulletin, 42,1,2007.

[20] H Sato, T Umeda, et.al, Synthesis of Mag. Glass Ceramics Based on Strontium,vol. 34, no. 1,1993, pp. 76-81.

[21] A.A Sattar, et.al, Rare Earth Doping Effect on the Electrical Properties of $\mathrm{Cu}-\mathrm{Zn}$ Ferrites, J. de Physique IV, 7, 1997, pp245-246.

[22] R.D Waldron., Infrared spectroscopy of ferrites, Phy. Rev, 1955, pp1727.

[23] Vasant Naidu et.al, Study of Electrical and Magnetic properties in Nano sized Ce-Gd Doped Magnesium Ferrite, Int. J of Comp. App, vol 27, No.5 ,2011, pp 4045.

[24] R.G Kulkarni., H Joshi., Comparison of magnetic properties of $\mathrm{MgFe}_{2} \mathrm{O}_{4}$ prepared by wet-chemical and ceramic methods, J.Solid State Chem, 64, 2,1986 , pp141.

[25] L.A Vermenko., T.Y Gridasova., and E.N Lukachina., The effect of addition of rare earth element oxides on the properties of nickel ferrite, Poroshk. Metall., 1973, 9 (129): pp52.

[26] O.M Hemeda., Effect of sintering on X-Ray and IR spectral behaviour of the $\mathrm{MnAl}_{\mathrm{X}} \mathrm{Fe}_{2-\mathrm{x}} \mathrm{O}_{4}$ ferrite system, $\mathrm{J}$ Magn. Magn. Mater, 156,1, 1996, pp29-38.

[27] C. G. Koops, On the Dispersion of Resistivity and Dielectric Constant of Some Semiconductors at Audio frequencies, Phys. Rev. 83, 1951, pp121-124. 